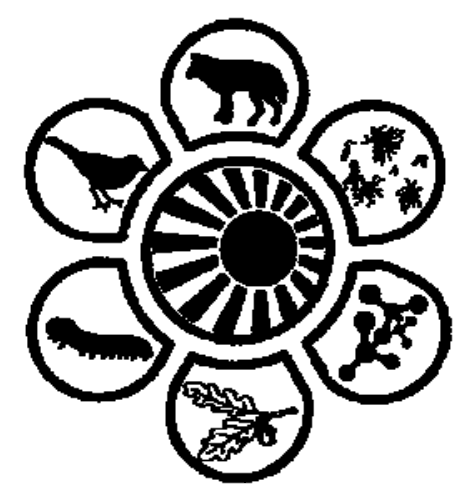

Вісник Дніпропетровського університету. Біологія, екологія. Vìsnik Dnìpropetrovs'kogo unìversitetu. Serîa Bìologîa, ekologìâ

Visnyk of Dnipropetrovsk University. Biology, ecology. 2013. 21(1)

ISSN 2310-0842

www.ecology.dp.ua

УДК 595.767.29:591.13

\title{
Играет ли сапрофагия существенную роль в питании Opatrum sabulosum (Coleoptera, Tenebrionidae)?
}

\author{
С.С. Назимов, В.В. Бригадиренко
}

Днепропетровский наџиональный университет имени Олеся Гончара, Днепропетровск, Украина

\begin{abstract}
Проанализирована роль сапрофагии в питании Opatrum sabulosum (L.) - одного из вредителей полевых культур, в первую очередь подсолненчика и кукурузы. Имаго данного вида чернотелок содержали в пластиковых садках, на субстрате из разных видов почв и подстилок естественных экосистем и агроценозов без доступа к растительной пище в течение 15 суток. Контрольную группу содержали без субстрата. Ежесуточно 720 экземпляров жуков взвешивали. При отсутствии корма отмечается практически линейное уменьшение масы тела имаго (к пятнадцатому дню - до 73,9\% от исходной массы). На черноземе обыкновенном легкоглинистом слабосмытом, среднесмытом и лугово-черноземных почвах достоверных отличий в динамике потери массы тела от контрольного варианата (без субстрата) не обнаружено. К 15-м суткам содержания имаго O. sabulosum (L.) на почвах посевов Helianthus annuus (L.), Zea mays (L.), Triticum durum (Dest.) и Brassica napus (L.) достоверных изменений массы тела также не зарегистрировано. Пребывание имаго в течение 15 суток на почве посевов Fagopyrum esculentum (Gilib.) и Beta vulgaris (L.) привело к снижению массы тела жуков по сравнению с контролем на 5,86\% и 8,02\% соответственно (вероятно из-за влияния пестицидной обработки, проводимой на полях данных культур). Для вариантов опыта с подстилкой из искусственного лесного насаждения, степного калдана и отмерших растительных остатков лугового фитоценоза тальвега балки достоверного изменения массы тела особей O. sabulosum (L.) не зарегистрировано. Жуки, находящиеся в садках с подстилкой (фрагменты хвои сосны, травянистых растений и листьев тополя черного), образованной на песчаных аллювиальных отложениях, достоверно снизили массу тела на $6,28 \%$ по сравнению с контрольной группой. Таким образом, увеличения массы тела особей $O$. sabulosum (L.) в садках с растительными остатками и почвой четырех обследованных экосистем не зарегистрировано. Результаты исследований показали, что детритофагия для даного вида чернотелок не характерна (по крайней мере ее роль в питании сильно преувеличена).
\end{abstract}

Ключевые слова: Opatrum sabulosum (Linnaeus, 1761); Tenebrionidae; пищевые предпочтения; устойчивость к потере влаги; лабораторные эксперименты

\section{Does saprophagy play a significant role in nutrition of Opatrum sabulosum (Coleoptera, Tenebrionidae)?}

\author{
S.S. Nazimov, V.V. Brygadyrenko \\ Oles Honchar Dnipropetrovsk National University, Dnipropetrovsk, Ukraine
}

Significance of the saprophagous diet for Opatrum sabulosum (Linnaeus, 1761), which is a pest of cultivated crops such as sunflower and maize, is under consideration. Imagoes of that darkling beetle were kept in plastic containers on substrates of different types of soils and litters of natural ecosystems and agricultural lands with no access to plant food for 15 days. The control group were kept in cases with no substrate. Every day 720 specimens of the beetles were weighed. If there is no food the almost linear decrease in imago body weight was detected (the $15^{\text {th }}$ day - up to $73.9 \%$ of the initial weight). Significant differences in the dynamics of weight loss of the beetles kept on the ordinary chernozem of different types and in cases without any substrate (control) were not found. By the $15^{\text {th }}$ day of the experiment the significant changes of weight of O. sabulosum (L.) imago kept on soils taken from the fields sown with Helianthus annuus (L.), Zea mays (L.),

Днепропетровский национальный университет имени Олеся Гончара, пр. Гагарина, 72, Днепропетровск, 49010, Украина. Тел.: +38050-939-07-88. E-mail: brigad@ua.fm.

Oles Gonchar Dnipropetrovsk National University, Gagarin ave., 72, Dnipropetrovsk, 49010. Ukraine.

Tel.: +38050-939-07-88.E-mail: brigad@ua.fm.

(C) С.С. Назимов, В.В. Бригадиренко, 2013 
Triticum durum (Dest.) and Brassica napus (L.) were also not registered. Keeping imagoes within 15 days on soils sown with Fagopyrum esculentum (Gilib.) and Beta vulgaris (L.) reduced the beetles' body weight by $5.86 \%$ and $8.02 \%$ respectively, as compared to the control (probably due to pesticidal treatment of the crops). In the experiments with the litter of artificial forest plantations, the steppe litter (kaldan) and dead plant debris from the thalweg's meadow the significant changes in the body weight were not registered. The beetles kept in containers with the litter (fragments of pine needles, grass and leaves of the black poplar) from the sandy alluvial soil significantly reduced the body weight by $6.28 \%$, as compared to the control group. Thus, the body weight gain of $O$. sabulosum (L.) kept in containers with the plant remains from the studied four ecosystems is not registered. The research results showed that the detritophagy is not typical for that darkling beetle (or at least its role in their feeding is greatly exaggerated).

Keywords: Opatrum sabulosum; Tenebrionidae; food preferences; laboratory experiments; resistance to moisture loss

\section{Введение}

Род Opatrum Fabricius, 1775 в мировой фауне представлен более чем 30 видами (Chernej, 2005; Leo et al., 2011). На территории Украины распространены три вида: O. triste Steven, 1829 (до высоты 300-400 м н.у.м. в Горном Крыму), O. riparium Scriba 1865 (Волынская обл., Шацкие озера, влажные биотопы) и O. sabulosum (Linnaeus, 1761) (различные биотопы всей территории Украины). Из указанных видов наибольшее хозяйственное значение практически по всему своему ареалу имеет последний.

O. sabulosum (L.) распространен (Chernej, 2005; Abdurahmanov and Nabozhenko, 2011) в Северной и Средней Европе, на Кавказе, на юге и в средней полосе Сибири, в Казахстане, в горных системах восточной части Средней Азии. Данный вид относится к числу наиболее изученных в экологическом плане, массовых и, одновременно, наиболее опасных видов насекомых с широким спектром питания (Minoranskij, 1978; Kabanov and Sedin, 1981; Minoranskij and Kuzina, 1987). Наибольший вред он причиняет в годы массового размножения (Chernej, 2005). В массе попадается на территории населенных пунктов, встречаясь даже на участках с очень высокой степенью фрагментации растительности (Fattorini, 2011).

По нашим данным и многочисленным литературным указаниям (Dolin, 1975; Knor, 1975; Kabanov, 1977, 1981; Parmenter and Macmahon, 1984), O. sabulosum (L.), обитает на различных типах почв: от легких песчаных и супесчаных до тяжелых суглинистых и глинистых. Переносит слабое засоление почвы: отмечен в степи в окрестностях солончаковых озер, хотя на солончаках отсутствует. В естественных биотопах численность вида выше на участках с разреженной растительностью. Во многих изданиях справочного характера (Chernej, $2005)$ вид указыватся как полифитофаг и детритофаг.

Имаго O. sabulosum (L.) живет два - три года (Dolin, 1975), зимует в верхних горизонтах почвы или подстилке. В апреле наблюдается массовое спаривание, в конце апреля - начале мая самки откладывают яйца. Кладки они располагают на глубине нескольких сантиметров. В одной кладке насчитывается от нескольких до десятка яиц. За год самка откладывает до 100 яиц (Dolin, 1975). Эмбриональное развитие в зависимости от температуры почвы длится в среднем две - три недели. Личинки в основном питаются гниющими растительными остатками. Окукливание обычно наблюдается через 35-40 дней после выхода личинки из яйца. Куколки открытые (Jia et al., 2013), свободно лежат между комочками почвы на глубине 3-6 см. Продолжительность стадии куколки 6-8 суток. Среди паразитов данного вида указывается
(Rejnhardt, 1936) тахина Stomatomyia acuminata Rond., в кишечнике зарегистрирована грегарина Stylocephalus oblongatus Watson.

По информации разных авторов (Medvedev, 1968), имаго охотно поедают основания стеблей, корни, вредят корнеплодам (кортофелю и свекле), проделывая в них узкие глубокие ходы. Имаго повреждают пшеницу, ячмень, овес, кукурузу, просо, сорго, суданку, фасоль, нут, чечевицу, свеклу, картофель, томаты, табак, подсолнечник, сафлор, хлопчатник, огурцы, арбузы, лук, фенхель, коноплю, лен, мак, рыжик, сурепку, рапс, горчицу, шалфей лекарственный, периллу, ляллеманцию, выгрызают семядоли плодовых культур, повреждают виноградную лозу (Medvedev, 1968). Повреждает молодые сосновые насаждения (Chernej, 2005). Особенно охотно жуки поедают части растений, начавшие увядать. Максимальная активность имаго отмечается ранней весной (Rejnhardt, 1936). Наибольшие повреждения сельскохозяйственным культурам жуки наносят в конце апреля - начале мая (Dolin, 1975). В это время на один квадратный метр регистрируется от нескольких десятков до сотни жуков. К середине лета процент активных имаго неуклонно понижается. Жуки нового поколения появляются в конце августа - начале сентября.

Питается (Rejnhardt, 1936) листьями естественной степной флоры, на полях переходит к питанию сорными растениями (спорыш, лебеда, марь, вьюнок полевой), иногда грызет сухие растительные остатки и сухой конский навоз.

Особенности рациона различных видов чернотелок исследованы довольно детально (Allsopp, 1980; Miller and Redfern, 1988; Rogers et al., 1988). Пространственная структура популяций чернотелок определяется комплексным воздействием гигротермического режима и растительного покрова конкретного участка (Whicker and Tracy, 1987; Parmenter et al., 1989a, 1989b; Semida et al., 2001), поэтому исследование пищевых предпочтений отдельного вида в полевых условиях невозможно (Wise, 1981). Традиционно считается, что в условиях недостатка пищи имаго и личинки большинства видов способны питаться отмершими растительными тканями, являясь сапрофагами (Byzova and Kelejnikova, 1964; CloudsleyThompson, 1975; Crawford, 1988). Процент сапрофагов в данном семействе повышается от умеренной к аридной зоне субтропиков (Carpaneto and Fattorini, 2001; Chen et al., 2004). Относительно рациона субтропических видов чернотелок информация фрагментарна, она не позволяет оценить реальное соотношение фито- и сапрофагии в их рационе (De Los Santos et al., 1988, 2002).

Цель данной работы - оценить изменение массы тела O. sabulosum (L.) в условиях питания различными типами растительныого опада, подстилки и почвы по став- 
нению с вариантом опыта, в котором доступ к потенциальным пищевым объектам полностью отсутствовал.

\section{Материал и методы исследований}

Cбор O. sabulosum (L.) осуществляли в начале июля 2012 г. в окрестностях г. Днепропетровск путем установки на степных участках с разреженным растительным покровом (на склонах балок) ловушек Барбера без фиксирующей жидкости, а также ручного сбора на полях пропашных культур (подсолнух и кукуруза). Перед началом эксперимента жуков содержали на оптимальном для их лабораторного содержания рационе (неограниченное количество листьев салата, капусты и виноградной лозы) при наличии доступа к воде.

Каждый эксперимент проводили в 6-кратной повторности (по 8 экз. O. sabulosum (L.) в одном пластиковом садке, размером $8 \times 12 \times 10 \mathrm{~cm}$, при равном соотношении самцов и самок). Всего в эксперименте участвовало 720 экз. имаго. Суточные колебания температуры воздуха находились в пределах $+25 \ldots+28{ }^{\circ} \mathrm{C}$. Чернотелок содержали на определенном виде субстрата (разные виды почв и подстилок), собранного в ненарушенных экосистемах и в агроценозах. При этом доступ у них к любой растительной или животной пище отсутствовал. Контрольная группа находилась в пластиковых садках без какого-либо субстрата. Во всех вариантах эксперимента доступа к воде у насекомых не было, почву или подстилку в садках не увлажняли на протяжении всего опыта. Эксперимент длился 15 суток, взвешивание жуков - ежесуточное. Массу определяли на аналитических весах JD-100 (точность - 1 мг). Обработку данных проводили в пакете программ Statistica 8.0. Вычисляли $M \pm m$, на диаграммах отражены медиана, верхний и нижний квартили и диапазон колебаний. Достоверными считали отличия между выборками при $P<0,05$.

\section{Результаты и их обсуждение}

При отсутствии корма (рис. 1a) отмечается практически линейное уменьшение масы тела имаго (к 15-м суткам - до 73,9\% от исходной массы). Содержание жуков в садке с песчаными аллювиальными отложениями (рис. 1б) ведет к нелинейному изменению массы тела (до 73,4\% исходной массы к 15-м суткам эксперимента). На черноземе обыкновенном легкоглинистом слабосмытом (рис. 16), среднесмытом (рис. 12) и лугово-черноземных почвах (рис. $1 \partial$ ) достоверных отличий $(P<0,001)$ динамики массы тела от контрольного варианата (без субстрата) не обнаружено (к 15-м суткам - до 75,1\%, $73,0 \%$ и 72,4\%, соответственно). Полученные результаты свидетельствуют $\left(P>0,05 ; F=1,06\right.$ при $\left.F_{0,05}=2,76\right)$ об отсутствии питания $O$. sabulosum (L.). как бедными супесчаными, так и богатыми черноземными и черноземно-луговыми типами почв из природных экосистем.

К 15-м суткам эксперимента (рис. 2) масса имаго составила для почв посевов Helianthus annuus (L.) 74,9\%, Zea mays (L.) - 70,8\%, Triticum durum (Dest.) - 73,2\%, Brassica napus (L.) - 74,1\%. Достоверных изменений массы тела $\left(P>0,05 ; F=0,86\right.$ при $\left.F_{0,05}=2,76\right)$ при нахо- ждении O. sabulosum (L.). в садках на почвах подсолнечникового, пшеничного, кукурузного и рапсового полей по сравнению с опытом без субстрата в садках не зарегистрировано.

Пребывание имаго на почве из-под посевов гречихи и свеклы привело к снижению массы тела жуков по сравнению с контролем на $5,86 \%$ и $8,02 \%$ соответственно $\left(P<0,05 ; F=7,04\right.$ и 8,50 при $\left.F_{0,05}=4,96\right)$.

Уменьшение массы тела при содержании жуков на почве с полей гречихи и свеклы привело к более сильному снижению массы тела по сравнению с контрольным вариантом опыта (вероятно из-за пестицидной обработки, проводимой на полях данных культур).

Для подстилки из искусственного лесного насаждения, степного калдана и отмерших растительных остатков лугового фитоценоза тальвега балки (рис. 3) достоверного изменения массы особей $O$. sabulosum (L.) не зарегистрировано $\left(P>0,05 ; F=0,62\right.$ при $\left.F_{0,05}=3,10\right)$.

Жуки, находящиеся в садках с подстилкой (фрагменты хвои сосны, травянистых растений и листьев тополя черного), образованной на песчаных аллювиальных отложениях, снизили $\left(P<0,05 ; F=8,66\right.$ при $\left.F_{0,05}=4,96\right)$ массу тела на 6,28\% по сравнению с контрольной группой. Вероятно, уменьшение массы тела жуков вызвано соединениями, поступающими из хвои сосны. Аналогичные данные получены нами при анализе динамики массы тела Rossiulus kessleri (Lohm.) (Diplopoda), который в течение 10-суточного питания хвоей сосны в лабораторном опыте снижал массу тела на 7,5\%.

Таким образом, увеличения массы тела особей O. sabulosum (L.) в садках с растительными остатками четырех обследованных экосистем не зарегистрировано. Это однозначно свидетельствует о том, что данный вид чернотелок не является детритофагом (фитосапрофагом).

Полученные результаты (см. рис. 1-3) согласуются между собой не только по интенсивности потери массы, но и по динамике данного процесса. По нашим лабораторным наблюдениям, потеря массы могла продолжаться и более длительный срок (однако данные эксперименты могли привести к массовой гибели жуков). Летние засухи в степной зоне Евразии продолжительностью 3-4 недели - обычное явление. Гибели жуков в природных экосистемах и агроценозах в это время не происходит благодаря их питанию зелеными тканями растений, питью росы.

Физиологические аспекты недостаточного уровня обеспеченности влагой у чернотелок изучены довольно детально. По данным S.G. Naidu и J. Hattingh (1986), обезвоживание в течение 6 суток при $+26^{\circ} \mathrm{C}$ у чернотелки Stips stali Haag, 1875 привело к потере массы тела на 7\% (в том числе к уменьшению массы гемолимфы на $33 \%$ ). Концентрация анионов и катионов в гемолимфе повышалась при дегидратации и снижалась при возобновлении нормального доступа к воде. Полученные нами данные для того же температурного диапазона, который исследован S.G. Naidu и J. Hattingh (1986), согласуются по темпам потери массы тела (в нашем эксперименте в течение первых 6 суток исследования у O. sabulosum (L.) при отсутствии корма и влаги она составила $8,2 \%$ ). 

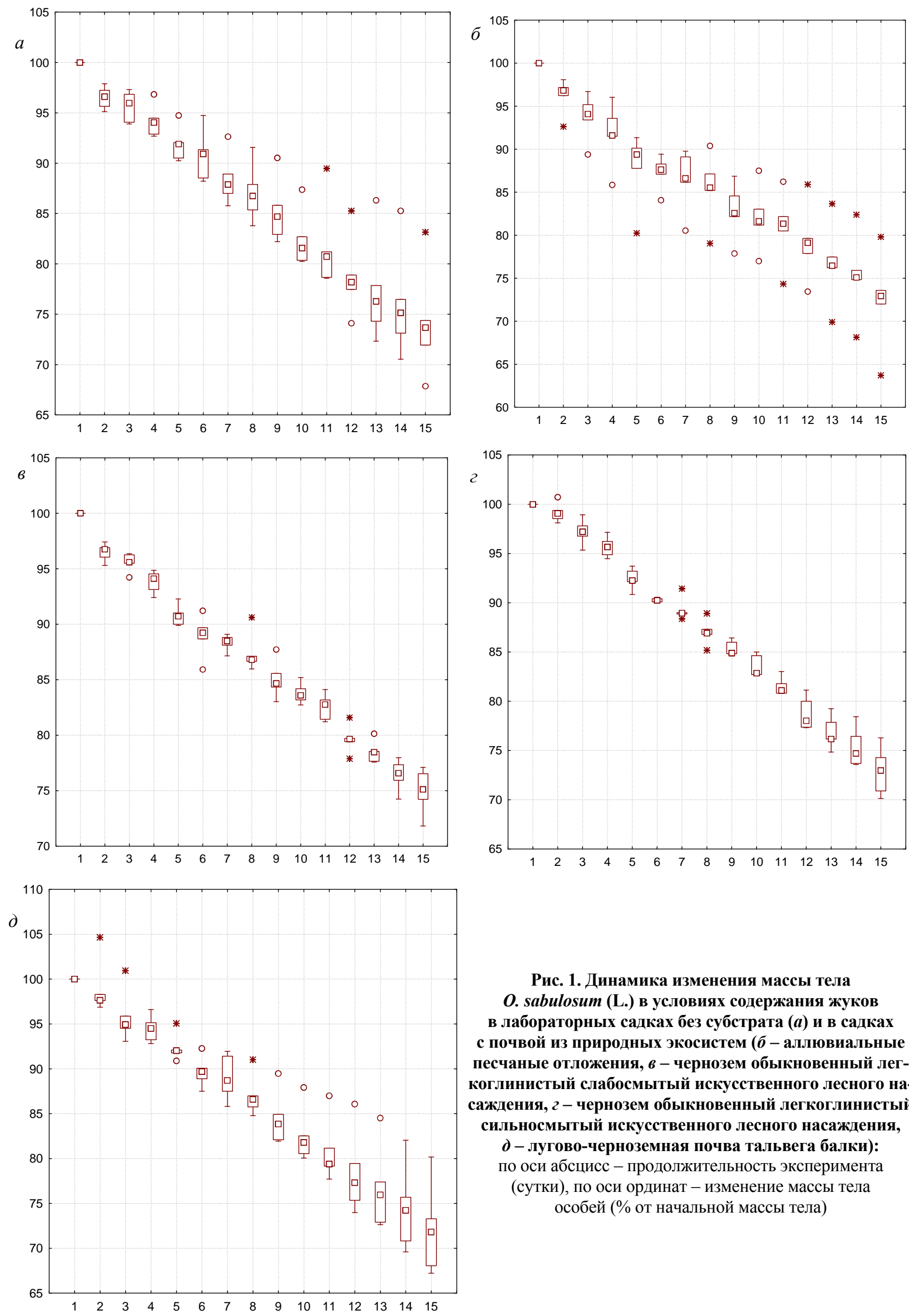

Рис. 1. Динамика изменения массы тела

O. sabulosum (L.) в условиях содержания жуков в лабораторных садках без субстрата $(a)$ и в садках с почвой из природных экосистем (б - аллювиальные песчаные отложения, $в$ - чернозем обыкновенный легкоглинистый слабосмытый искусственного лесного насаждения, 2 - чернозем обыкновенный легкоглинистый сильносмытый искусственного лесного насаждения,

д - лугово-черноземная почва тальвега балки): по оси абсцисс - продолжительность эксперимента (сутки), по оси ординат - изменение массы тела особей (\% от начальной массы тела) 

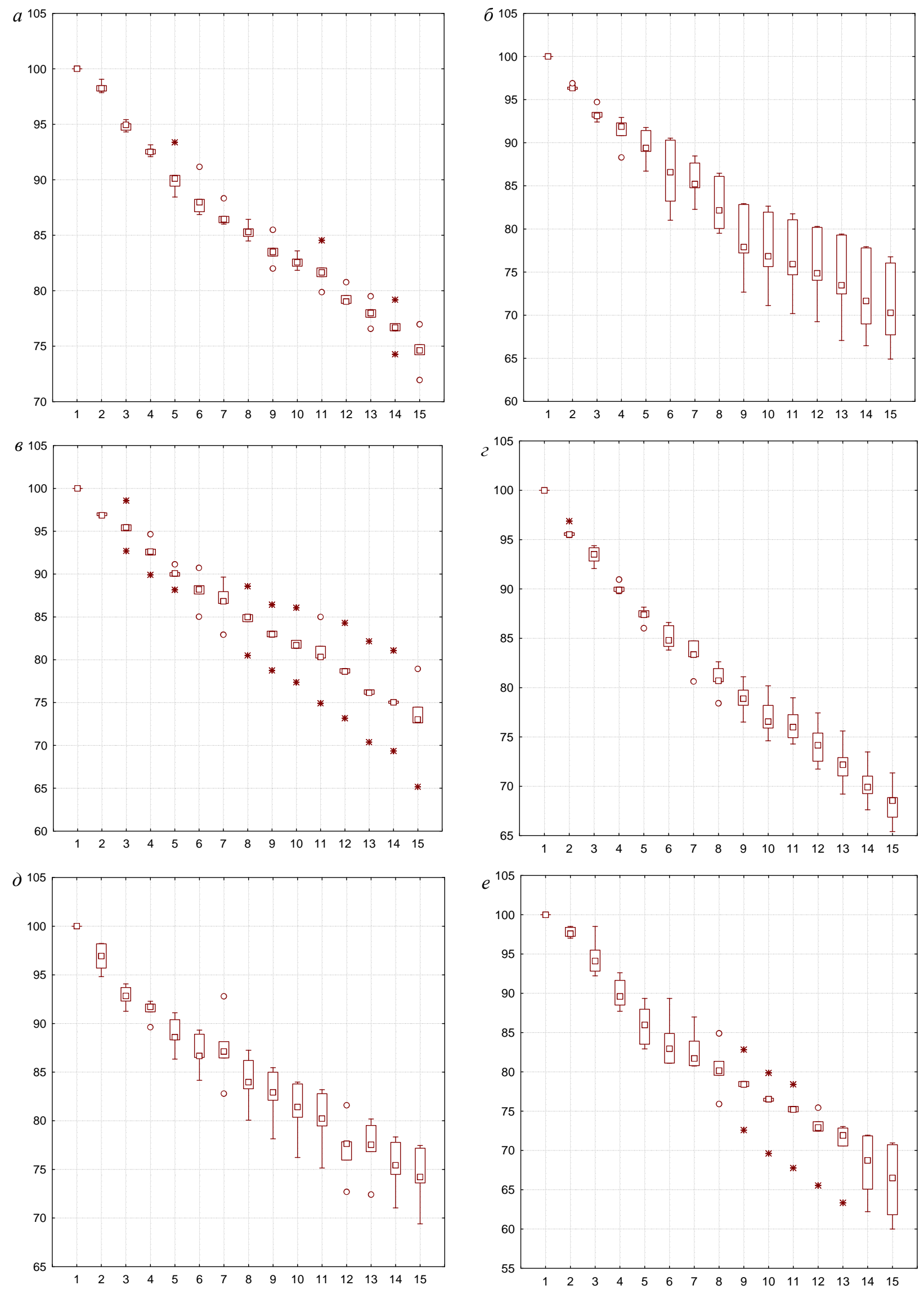

Рис. 2. Динамика изменения массы тела $O$. sabulosum (L.) в лабораторных садках с почвой агроценозов: $a$ - почва под посевами Helianthus annuus (L.), 6 - Zea mays (L.), в - Triticum durum (Dest.), 2-Fagopyrum esculentum

(Gilib.), d-Brassica napus (L.), e - почва по посевами Beta vulgaris (L.); по оси абсцисс - продолжительность эксперимента (сутки), по оси ординат - изменение массы тела особей (\% от начальной массы тела) 

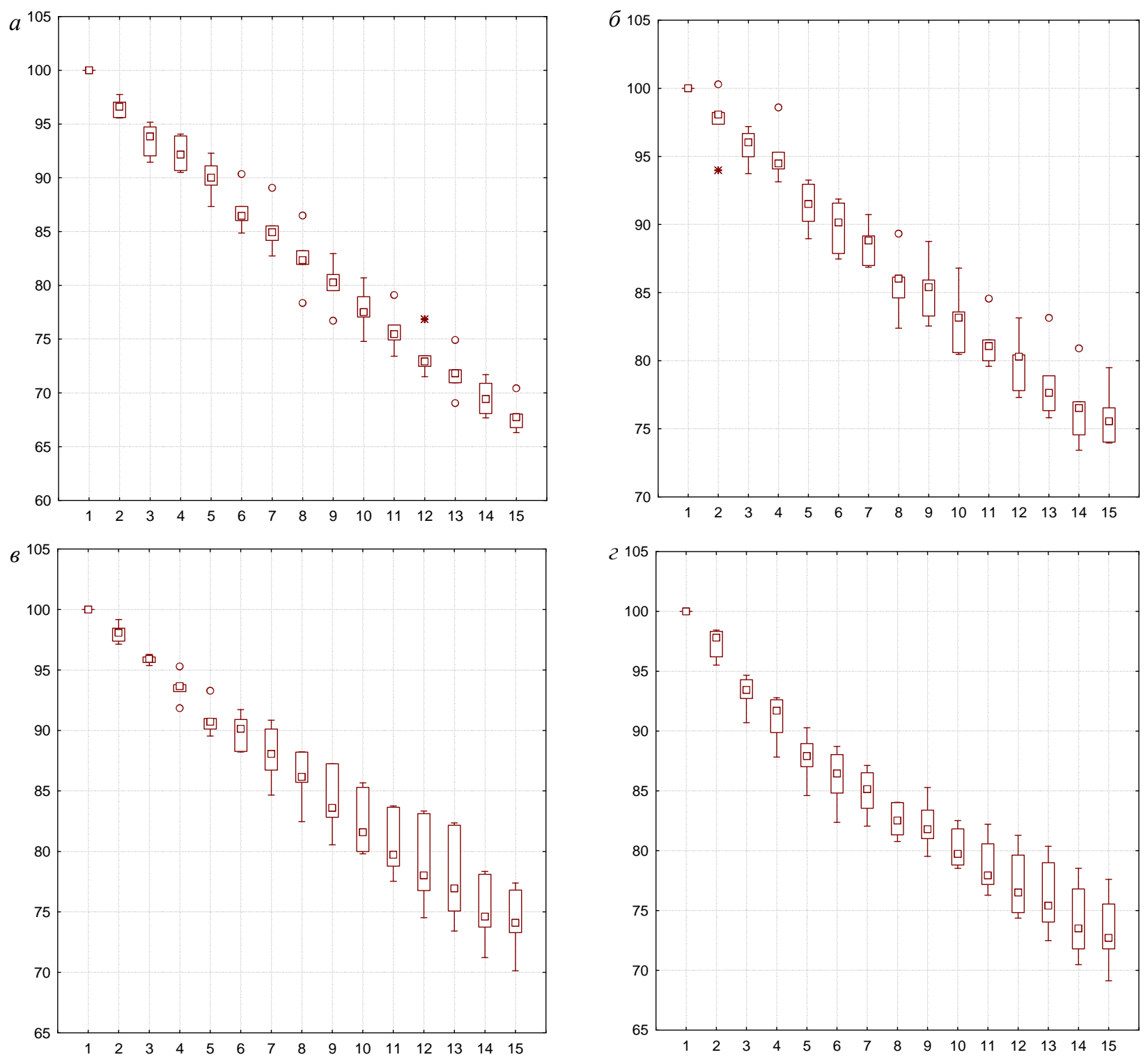

Рис. 3. Динамика изменения массы тела O. sabulosum (L.) в лабораторных садках с подстилкой из природных экосистем: $a$ - подстилка с поверхности песчаных аллювиальных отложений, $\sigma$ - подстилка из искусственного лесного насаждения, 8 - степной калдан (фрагменты отмершей степной растительности), г - отмершие растительные остатки из лугового фитоценоза в тальвеге балки; по оси абсцисс - продолжительность эксперимента (сутки), по оси ординат - изменение массы тела особей (\% от начальной массы тела)

U. Gehrken и L. Sømme (1994), исследуя процессы выживания марокканских чернотелок в условиях высокогорья, установили, что Opatrum rhaticus Antoine, 1936 переносил в живом состоянии обезвоживание более чем на 50\% исходной массы тела. Интенсивность физиологических процессов у данного вида в ночное время была на более высоком уровне для особей, пойманных в Атласских горах на высоте 3100 м, по сравнению с экземплярами, собранными на высоте 2600 м. У исследованных данными авторами чернотелок потери воды и смертность были минимальными по сравнению с изученными ими видами семейства долгоносиков, листоедов и жужелиц, отловленных в тех же биотопах. По результатам наших исследований, критической для $O$. sabulosum (L.) является потеря 30\% массы тела (при отсутствии питания растительными или животными тканями и водой).

\section{Выводы}

Роль детритофагии (фитосапрофагии) в питании Opatrum sabulosum (L.) очень низка. При полном отсутствии корма отмечалось линейное уменьшение массы тела чернотелок (на 15-е сутки - до 73,9\% от исходной массы). В то же время на лугово-черноземной почве и черноземе обыкновенном легкоглинистом слабосмытом и среднесмытом явных отличий в динамике потери массы тела от контрольных вариантов (вариант опыта без почвы и подстилки) не обнаружено. На 15-е сутки опыта масса имаго O. sabulosum (L.) при содержании на почвах из-под посевов Helianthus annuus (L.), Zea mays (L.), Triticum durum (Dest.) и Brassica napus (L.) достоверных изменений массы тела также не зарегистрировано. 
Пребывание имаго в течение 15 суток на почве из-под посевов посевов Fagopyrum esculentum (Gilib.) и Beta vulgaris (L.) привело к снижению массы тела чернотелок по сравнению с контролем соответственно на 5,86\% и 8,02\% (вероятно из-за пестицидной обработки, проводимой на полях данных культур).

В вариантах опыта с подстилкой из искусственного лесного насаждения, степного калдана и отмерших растительных остатков лугового фитоценоза тальвега балки достоверного изменения массы тела особей $O$. sabulosum (L.) не зарегистрировано. Чернотелки, находящиеся в контейнерах с подстилкой (фрагменты листьев тополя черного, хвои сосны и отмершие остатки травянистых ратсений), образованной на речных песчаных аллювиальных отложениях, достоверно снизили массу тела (на 6,28\% по сравнению с контролем).

Исходя из вышеуказанного можно утвержадать, что увеличения массы тела особей $O$. sabulosum (L.) в садках с растительными остатками четырех обследованных экосистем не происходит.

\section{Библиографические ссылки}

Abdurahmanov, G.M., Nabozhenko, M.V., 2011. Opredelitel' Katalog Zhukov-Chernotelok (Coleoptera, Tenebrionidae s. str.) Kavkaza i Juga Evropejskoj Chasti Rossii [The Identification Keys and the Catalog of Darkling Beetles (Coleoptera, Tenebrionidae s. str.) of the South Caucasus and the European Part of Russia]. Moskow, KMK Scientific Press Ltd. (in Russian).

Allsopp, P.G., 1980. The biology of false wireworms and their adults (soil-inhabiting Tenebrionidae) (Coleoptera): A review. Bull. Entomol. Res. 70, 343-379.

Byzova, J.B., Kelejnikova, S.I., 1964. Semejstvo Tenebrionidae - Chernotelki [The family Tenebrionidae - darkling beetles]. In: Giljarov, M.S. (Ed.). Opredelitel' Obitajushhih v Pochve Lichinok Nasekomyh [The Identification Keys of Soil Dwelling Insect Larvae]. Moskow, Nauka, 463-496 (in Russian).

Carpaneto, G.M., Fattorini, S., 2001. Spatial and seasonal organisation of a darkling beetle (Coleoptera, Tenebrionidae) community inhabiting a Mediterranean coastal dune system. Ital. J. Zool. 68, 207-214.

Chen, X., Thompson, M.B., Dickman, C.R., 2004. Energy density and its seasonal variation in desert beetles. J. Arid Environ. 56, 559-567.

Chernej, L.S., 2005. Zhuki-chernotelki (Coleoptera, Tenebrionidae) [Darkling beetles (Coleoptera, Tenebrionidae)]. Kiev, Naukova dumka (in Russian).

Cloudsley-Thompson, J.L., 1975. Adaptations of Arthropoda to arid environments. Annu. Rev. Entomol. 20, 261-283.

Crawford, C.S., 1988. Nutrition and habitat selection in desert detritivores. J. Arid Environ. 14, 111-121.

De Los Santos, A., Alonso, E.J., Hernández, E., Pérez, A.M., 2002. Environmental correlates of darkling beetles population size (Coleoptera, Tenebrionidae) on the Cañadas of Taide in Tenerife (Canary Islands). J. Arid Environ. 50, 287-308.

De Los Santos, A., Montes, C., Ramírez, L., 1988. Life histories of some darkling beetles (Coleoptera: Tenebrionidae) in two Mediterranean ecosystems in the lower Guadalquivir (southwest, Spain). Environ. Entomol. 17, 799-814.

Dolin, V.G., 1975. Chernotelki - Tenebrionidae [The family of Darkling beetles - Tenebrionidae] In: Vasil'ev, V.P. (Ed.). Vrediteli Sel'skohozjajstvennyh Kul'tur i Lesnyh Na- sazhdenij [Pests of Agricultural Crops and Forest Plantations]. Kiev, Urozhaj. 2, 9-21 (in Russian).

Fattorini, S., 2011. Insect extinction by urbanization: A long term study in Rome. Biol. Conserv. 144(1), 370-375.

Gehrken, U., Sømme, L., 1994. Tolerance of desiccation in beetles from the High Atlas Mountains. Compar. Biochem. Physiol. 109A(4), 913-922.

Jia, L., Guo-Dong, R., You-Zhi, Y., 2013. Descriptions of eleven Opatrini pupae (Coleoptera, Tenebrionidae) from China. ZooKeys 291, 83-105.

Kabanov, V.A., 1977. Biologija peschanogo medljaka (Opatrum sabulosum L.) v lesostepnoj i stepnoj zonah Evropejskoj chasti SSSR [Biology of Opatrum sabulosum L. in the forest-steppe and steppe zones of the European part of the USSR]. Nauchnye Doklady Vysshej Shkoly. Biologicheskie Nauki [Scientific Reports of High School. Biological Sciences] 9, 47-53 (in Russian).

Kabanov, V.A., 1981. O troficheskih svjazjah polevyh vidov zhukov chernotelok (Tenebrionidae) [On the trophic relations of field species of darkling beetles (Tenebrionidae)]. Vestnik Zool. 4, 82-85 (in Russian).

Kabanov, V.A., Sedin, I.F., 1981. Biologija polevyh vidov chernotelok Evropejskoj chasti SSSR [Field species Biology of darkling beetles in the European part of the USSR]. Fauna i Jekologija Bespozvonochnyh Lesostepnoj Zony. Nauchnye Trudy Kurskogo pedagogicheskogo instituta [Invertebrate Fauna and Ecology of the Forest-Steppe Zone. Scientific Papers of the Kursk Pedagogical Institute] 210, 86-93 (in Russian).

Knor, I.B., 1975. Life cycles of darkling beetles (Coleoptera, Tenebrionidae) of Tuva. Sov. J. Ecol. 6, 458-461.

Leo, P., Soldati, F., Soldati, L., 2011. A new species of the genus Opatrum Fabricius from south-eastern Corsica (Insecta: Coleoptera: Tenebrionidae). Ann. Zool. 61(2), 277-280.

Medvedev, S.I., 1968. Zhuki-chernotelki (Tenebrionidae) [Darkling beetles (Tenebrionidae)]. Moskow - Leningrad, Nauka (in Russian).

Miller, R.W., Redfern, R.E., 1988. Feed additives for control of lesser mealworm (Coleoptera: Tenebrionidae) in poultry broiler houses. J. Econ. Entomol. 81, 1137-1139.

Minoranskij, V.A., Kuzina, Z.R., 1987. Morphometric changes in the cellar beetle Opatrum sabulosum under the effect of automobile exhausts. Bioindikatsiya Promyshlennykh Zagryaznenii [Bioindication of Industrial Pollution], Volgograd, 10-15 (in Russian).

Minoranskij, V.A., 1978. Nekotorye osobennosti biologii i povedenija peschanogo medljaka Opatrum sabulosum L. (Coleoptera, Tenerionidae) na Severnom Kavkaze [Some features of the biology and behavior of Opatrum sabulosum L. (Coleoptera, Tenerionidae) in the North Caucasus]. Entomol. Review 57(1), 37-47 (in Russian).

Naidu, S.G., Hattingh, J., 1986. Water balance and osmoregulation in Stips stali, a nocturnal tenebrionid beetle from the Namib Desert. J. Insect Physiol. 32(10), 891-896.

Parmenter, R.R., Macmahon, J.A., 1984. Factors influencing the distribution and abundance of ground-dwelling beetles (Coleoptera) in a shrub-steppe ecosystem: The role of shrub architecture. Pedobiology 26, 21-34.

Parmenter, R.R., Parmenter, C.A., Cheney, C.D., 1989a. Factors influencing microhabitat partitioning among coexisting species of arid-land darkling beetles (Tenebrionidae): Behavioral response to vegetation architecture. Southwest. Nat. 34, 319-329.

Parmenter, R.R., Parmenter, C.A., Cheney, C.D., 1989b. Factors influencing microhabitat partitioning among coexisting species of arid-land darkling beetles (Tenebrionidae): Temperature and water conservation. J. Arid Environ. 17, 57-67.

Rejnhardt, A.N., 1936. Zhuki-chernotelki triby Opatrini Palearkticheskoj oblasti [Darkling beetles of the tribe Opatrini of 
Palearctic region]. Moskow, Leningrad, Izdatel'stvo AN SSSR (in Russian).

Rogers, L.E., Woodley, N.E., Sheldon, J.K., Beedlow, P.A., 1988. Diets of darkling beetles (Coleoptera: Tenebrionidae) within a shrub-steppe ecosystem. Ann. Entomol. Soc. Am. 81, 782-791.

Semida, F.M., Abdel-Dayem, M.S., Zalat, S.M., Gilbert, F.S., 2001. Habitat heterogeneity and altitudinal gradients in rela- tion to beetle diversity in South Sinai, Egypt. Egypt. J. Biol. $3,137-146$.

Whicker, A.D., Tracy, C.R., 1987. Tenebrionid beetles in the shortgrass prairie: Daily and seasonal patterns of activity and temperature. Ecol. Entomol. 12, 97-108.

Wise, D.H., 1981. A removal experiment with darkling beetles: Lack of evidence for interespecific competition. Ecology 62, 727-738.

Надійшла до редколегії 21.02.2013 